\title{
Segurança, Liberdade e Concórdia no Pensamento Republicano de Espinosa $\overbrace{}^{\Uparrow}$
}

[Security, Freedom and Concordia in Spinoza's Republican Thought]

\section{Stefano Visentin ${ }^{\star \star}$}

Resumo: O artigo pretende apresentar a construção dos conceitos de segurança e liberdade nos escritos políticos de Espinosa, para rearticular sua construção em diálogo com a tradição humanista, mais especificamente de Thomas More e Erasmo de Rotterdam. Tal diálogo será relacionado com o problema da pietas, no seu aspecto moral, e a concordia, em seu aspecto político, para serem reconsiderados e articulados com o realismo político introduzido por Maquiavel e Hobbes. Finalmente, pretendemos analisar a peculiaridade do filósofo holandês, problematizando tais conceitos na escrita do Tratado teológico-político e do Tratado Político.

Palavras-chave: Espinosa, Humanismo, Política, Segurança e Liberdade.

\begin{abstract}
This paper intends to present the construction of the concepts of security and freedom in the Spinoza's political writings, rethinking its construction in dialogue with the humanist tradition, most specifically with Thomas More and Erasmus of Rotterdam. This dialogue is related to the humanist problem of pietas, in the moral aspect, and concordia, in politics aspect, to be reconsidered and articulated with the political realism introduced by Machiavel and Hobbes. Finally, we aim to analyze the peculiarity of the dutch philosopher, problematizing such concepts in the Theological-political Treatise and the Political Treatise.
\end{abstract}

Keywords: Spinoza, Humanism, Politics, Security, and Freedom.

\section{1 - A tradição irenista nos Países Baixos dos séculos XVI e XVII}

Em 1517, Erasmo de Rotterdam publicou a Querela Pacis, considerada, juntamente com a Uto- pia por Thomas More, o manifesto mais significativo do humanismo do século XVI $[1$. Os fundamentos da defesa erasmiana da paz são essencialmente a pietas cristã, no referente à moral, e a busca cons-

\footnotetext{
${ }^{\star}$ Uma versão anterior e distinta deste artigo foi publicada em inglês na Revista Theoria, vol. 66, n. 15, 2019. Tradução desta versão por Ericka Marie Itokazu e Marília Pacheco.

${ }^{* *}$ Professor assistente (ricercatore confermato) de História das Doutrinas Políticas no Departamento de Economia, Sociedade e Política (Desp) da Università di Urbino "Carlo Bo", e professor da Scuola di Scienze politiche e sociali. E-mail: stefano.visentin@uniurb.it. ORCID: http://orcid.org/0000-0001-6963-4798.

${ }^{1}$ Il lamento della pace. Testo latino a fronte, Federico Cinti (org.), com um ensaio de Jean-Claude Margolin, Milão: BUR, 2005.
} 
tante da concordia, no referente à política; em particular, esta última torna-se, nas décadas seguintes, um elemento de grande importância dentro do debate político e religioso, distinguindo-se da tolerância que insiste na necessidade de aceitar a coexistência de uma pluralidade de fés no interior do mesmo espaço político contrariamente à concórdia, que visa construir um terreno comum para as diferentes correntes do cristianismo: em outros termos, enquanto a tolerância quer "despolitizar" a religião (segundo a famosa frase pronunciada por Michel de L'Hospital, em 1562, segundo a qual “il n'est pas icy de constituenda religione, sed de constituenda republica; et plusieurs peuvent estre cives, qui non erunt christiani" 27), a concórdia, diversamente, propõe a tarefa de transformar a política segundo uma perspectiva religiosa ${ }^{3}$.

O legado erasmiano percorre todo o século XVI, influenciando também muitos teólogos reformados, como Sébastien Castellion na França, Sebastian Franck na Ale- manha, Dirck Coornhert nos Países Baixos 4 . Especialmente nos Países Baixos, entre o final do século XVI e o começo do século seguinte, numerosas tentativas são feitas para elaborar e colocar em prática uma doutrina religiosa fundada em dogmas universalmente aceitos por todas as crenças cristãs presentes no território: e uma das tentativas mais originais é realizada por um grupo de crentes, provenientes de diferentes seitas (calvinistas, arminianos, menonitas, quakers, socinianos), chamados Colegiantes, que estabelecem uma comunidade fundada exclusivamente na leitura comum do texto bíblico e na prática do amor fraterno5. Sabe-se que alguns amigos de Espinosa participam desses encontros denominados colloquia prophetica, entre os quais certamente Jarig Jelles e Pieter Balling, e que provavelmente o próprio Espinosa o frequenta durante sua estada em Rijnsburg, no início dos anos 60 do século XVII6.

Em resumo, não há dúvida de que o contexto histórico e biográfico no qual Espinosa amadurece a

\footnotetext{
2 de L'HOSPITAL, M. (1561). Oeuvres complètes de Michel de L'Hospital. Ed. por P.S.J. DUFEY, vol. 1, Paris: Boulland, 1824-5, p. 452.

3 Sobre este tema, veja-se TURCHETTI, M. "Religious Concord and Political Tolerance in Sixteenth- and Seventeenth-Century France" in Sixteenth Century Journal, 1/22, 1991, pp. 15-25.

${ }^{4}$ Cfr. BIETENHOLZ, P.G. Encounters with a Radical Erasmus: Erasmus' Work as a Source of Radical Thought in Early Modern Europe. Toronto: Toronto University Press, 2009.

${ }^{5}$ FIX, A.C. Prophecy and Reason. The Dutch Collegiants in the Early Enlightenment. Princeton: Princeton University Press, 1990.

${ }^{6}$ Cfr. NADLER, S. Spinoza. A Life. Cambridge: Cambridge University Press, 1999, cap. 7.
} 
escrita do Tratado teológico-político exerce sobre ele uma influência "erasmiana", no sentido de uma busca de como estabelecer uma república livre e pacífica, tanto no seu próprio interior, quanto no confronto com os outros Estados; e de fato o subtítulo do livro já mostra essa orientação: "em que se demonstra que a liberdade de filosofar não só é compatível com a preservação da piedade e da paz como, inclusivamente, não pode ser abolida sem se abolir ao mesmo tempo a paz da república e a própria piedade" 7 .

No entanto, ao lado do ideal humanista irênico, uma reflexão teológico-política se desenvolveu na República das Províncias Unidas durante o século XVII, colocando o realismo político no centro da cena e inspirando-se no pensamento de Nicolau Maquiavel e Thomas Hobbes 8 . Sem aprofundar a recepção do trabalho desses dois autores na Holanda seiscentista, é preciso lembrar que tanto o desenvolvimento do neoestoicismo nas universidades quanto o do republicanismo fora do mundo acadêmico são afetados fundamentalmente pela lei- tura e discussão dos escritos do secretário florentino e do filósofo inglês. Em particular, nesse arcabouço teórico marcado por uma abordagem realista da natureza e da política humanas, o espaço para um elogio e a busca pela concórdia entre indivíduos e Estados parece ter sido reduzido ao mínimo, senão até mesmo cancelado.

Espinosa conhece bem o trabalho desses dois escritores "malditos", cita-os em seus escritos e extrai muitas ideias - em particular, mas não apenas, do "agudíssimo Maquiavel"; consequentemente, seria muito difícil acreditar que a reflexão espinosana sobre a paz e a concórdia não seja afetada pela crítica maquiaveliana e hobbesiana da visão humanista da religião e da política.

\section{2 - Paz, concórdia e liberdade no Tratado teológico-político}

No Tratado Teológico-Politico, Espinosa repetidamente insiste na necessidade de instituir, dentro da república holandesa, uma coexistência pacífica entre as diferentes fés religiosas. O prefácio, por

\footnotetext{
${ }^{7}$ Tratado Teológico-político. Tradução, introdução e notas de Diogo Pires Aurélio. Lisboa: Imprensa NacionalCasa da Moeda, 2004, p. 121. Doravante: TTP.

${ }^{8}$ Sobre a recepção de Maquiavel cfr. HAITSMA MULIER, E.O.G. "A Controversial Republican: Dutch Views on Machiavelli in the Seventeenth and Eighteenth Centuries” in BOCK, G., SKINNER, Q., VIROLI. M. (orgs.); Machiavelli and Republicanism. Cambridge: Cambridge University Press, 1990, pp. 247-263; sobre a recepção de Hobbes cfr. SECRÉTAN, C. "La réception de Hobbes aux Pays-Bas au XVIIéme siècle" in Studia Spinozana 3, 1987, pp. 27-46.
} 
exemplo, contém um elogio da república, "onde se concede a cada um inteira liberdade de julgar e de prestar culto a Deus à sua maneira, e onde não há nada que se considere mais caro e mais doce que a liberdade" 4 . Um elogio análogo, dirigido no entanto apenas a Amsterdã, está presente no capítulo final, onde Espinosa escreve que na cidade holandesa "todos os homens, seja qual for a sua nação e sua seita, vivem na mais perfeita concórdia"10, No seu estudo da república teocrática fundada por Moisés, também surgem razões pelas quais um governo republicano é naturalmente levado a apoiar a paz e a concórdia em vez de fomentar a guerra e as divisões internas. De fato, a história judaica mostra que os ritos e cerimônias religiosas desempenharam um papel político fundamental (na verdade, eles foram endereçados "à contingente felicidade do corpo e do Estado" (11), uma vez que envolveram toda a comunidade sem a necessidade de um clero que agisse como um corpo separado - e, de fato, foi precisamente o nascimento de um aparato eclesiástico distinto da co- letividade de fiéis que produziu a degeneração da república - e dessa maneira gerou uma "narrativa compartilhada" ${ }^{12}$ que consolidou as relações afetivas e a confiança mútua entre os cidadãos.

Geralmente, a reconstrução historiográfica que Espinosa realiza da república mosaica (em particular no capítulo XVII) e os ensinamentos políticos que dela deduz (no capítulo XVIII) propõemse a dois objetivos fundamentais: (1) mostrar o perigo que todo organismo político corre quando o clero se torna um poder separado da comunidade e, assim, assumindo um papel político mantido para si; (2) enfatizar a superioridade de um governo exercido por todo o povo com relação ao governo monárquico: uma superioridade baseada no imaginário coletivo, que apesar do risco sempre presente de se tornar superstição, dispõe da potência para estabelecer um regime no qual, pelo menos por um certo período, reinem a pietas religiosa e a concórdia.

Ao lermos o último capítulo do Tratado - cujo título afirma: "onde se demonstra que numa republica livre é uma lícito a cada um pen-

\footnotetext{
9 TTP, p. 127.

10 TTP. p. 390.

11 TTP, p. 191.

12 Retomo estes termos de JAMES, S. "Narrative as the means to freedom: Spinoza on the uses of imagination" in MELAMED, Y.Y., ROSENTHAL, M.A. (orgs.). Spinoza's Theological-Political Treatise. A Critical Guide. Cambridge: Cambridge University Press, 2010, pp. 250-267.

13 TTP, p. 383.
} 
sar o que quiser e dizer aquilo pensa' ${ }^{13}$ - tendo em mente o ensinamento dos capítulos históricos, então a liberdade, a piedade e a paz não só aparecem inextricavelmente conexas, mas também juntas elas contribuem para a forma democrática da república, que Espinosa considera o melhor regime, orientando seus leitores nessa direção. A referência à paz, portanto, não expressa simplesmente a necessidade de garantir a cada cidadão um espaço intangível por parte das autoridades, no interior do qual ele possa pensar e dizer aquilo em que acredita sem medo de ser perseguido, ao contrário, a paz é a expressão da participação ativa de todos na discussão pública, seja sobre os princípios da religião, seja sobre os assuntos do Estado: somente se os cidadãos participam das decisões políticas, de modo que visem ao bem comum, é possível afirmar, como no capítulo XVI, que "numa república e num Estado, onde a lei suprema é a salvação de todo o povo e não daquele que manda, quem obedece em tudo ao soberano não deve dizer-se escravo e inútil a si mesmo, mas apenas súdito" ${ }^{14}$. Esta referência à figura do "súdito" é particularmente interessante porque quebra a oposição dicotômica entre o escravo e o homem livre - típica em muitos aspectos da ideologia republicana da época -, abrindo espaço para uma concepção dinâmica de liberdade individual, que Espinosa define a partir da evolução do sistema de relações sociais e políticas na direção de uma república livre -, isto é, daquela em que "se liberta" das restrições da superstição e da dominação do homem pelo homem. Analogamente, a defesa extrema da liberdade de expressão no Tratado teológico-político constitui o "grau zero" de um percurso de emancipação, que procede de uma concepção individualista de tolerância mútua para o envolvimento de cada cidadão na constituição de uma "paz ativa", ou melhor, de uma concórdia universal entre os corpos e mentes de cada um, integrando imaginação e razão ${ }^{15}$.

Neste ponto, resta entender quais serão, de acordo com Espinosa, os instrumentos que permitem a uma república estabelecer e defender a paz e a concórdia, sem pôr em risco a segurança comum. Este último passo requer

\footnotetext{
14 TTP, p. 331.

15 Sobre esta passagem decisiva da reflexão política de Espinosa, veja-se dois recentes artigos que seguem em direção análoga: JAMES, S. "Narrative as the means to freedom: Spinoza on the uses of imagination" , cit., e SKEAFF, C. Becoming Political. Spinoza's Vital Republicanism and the Democratic Power of Judgment, Chicago: Chicago University Press, 2018.
} 
levar em consideração o segundo escrito político espinosista, o Tratado político.

\section{3 - O processo coletivo de cons- trução da paz no Tratado político}

A transição do primeiro para o segundo Tratado de Espinosa apresenta imediatamente um problema teórico relevante, que diz respeito precisamente à relação entre liberdade, paz e segurança. De fato, enquanto nas últimas páginas do Tratado Teológico-Político aparece a famosa definição segundo a qual "o verdadeiro fim da república é, de fato, a liberdade $^{116}$, por outro lado o Tratado Político principia por uma afirmação que parece ir na direção oposta:

Nem importa, para a segurança do estado, que ânimo dos homens sejam induzidos a administrar corretamente as coisas, contanto que as coisas sejam corretamente administradas. A liberdade de ânimo, ou fortaleza, é com efeito uma virtude privada, ao passo que a segurança é a virtude do es- $\operatorname{tado} 17$

Essas duas afirmações têm sido interpretadas como um sinal de mudança na atitude de Espinosa em relação à situação política de seu país, uma mudança em direção a um maior realismo (ou pessimismo) do que o Tratado TeológicoPolítico mais "militante" e democrático: no segundo Tratado, a segurança torna-se assim um elemento a ser salvaguardado mais importante que a liberdade e, portanto, a paz deve ser entendida mais como tolerância e respeito mútuo do que como concórdia e união dos ânimos.

$\mathrm{Na}$ realidade, uma leitura mais cuidadosa mostra que as coisas são mais complexas e que não é possível contrapor claramente os dois escritos. Em primeiro lugar, mesmo no primeiro Tratado, a segurança é considerada um objetivo fundamental de todo regime político e, em particular, da república, cujo objetivo é

não é dominar nem conter os homens pelo medo e submetê-los a um direito alheio; é, pelo contrário, libertar o indivíduo do medo a fim de que ele

\footnotetext{
16 TTP, p. 383.

17 Tratado Político. Tradução, introdução e notas de Diogo Pires Aurélio, revisão de Homero Santiago. São Paulo: WMF Martins Fontes, 2009, p. 9. Doravante: TP.
} 
viva, tanto quanto possível, em segurança, isto é, a fim de que ele preserve o melhor possível, sem prejuízo para si ou para os outros, o seu direito natural a existir e a agir. ${ }^{18}$

Nessas páginas, portanto, Espinosa mostra como a questão da segurança está implicada na da liberdade; por outro lado, no Tratado Político, parece que entre os dois planos há uma distinção clara, uma vez que a primeira diz respeito à esfera pública, enquanto a segunda parece estar confinada à dimensão da existência individual ou, ainda, da vida "privada", para a qual a paz dependeria mais da criação de um espaço de segurança individual do que da interação entre os cidadãos, como se Espinosa tivesse assumido uma inclinação "hobbesiana" (isto é, negativa) em relação à possibilidade de estabelecer um espaço comum de concórdia no interior do Estado.

Neste ponto, é necessário aprofundar as teses presentes no Tratado político. Dois são os aspectos mais significativos que devem ser evidenciados: (1) o tema da segu- rança é assumido por Espinosa no interior de um regime temporal imaginário como uma medida de flutuações afetivas, no sentido de que a busca por segurança se exprime como uma tentativa de quebrar definitivamente a sucessão contínua de medo e esperança que produz incerteza e mal-estar nos homens ${ }^{19}$; (2) se a segurança é o objetivo do Estado, contudo, nem todo regime político é adequado para garanti-lo: na verdade, um Estado é seguro somente se for organizado de modo a defender seus súditos não apenas de ameaças externas, mas também de perigos "internos" . Assim, evitase, por um lado, que a sociedade se polarize em grupos de indivíduos sui juris e alterius juris - ou ainda, estes subordinados àqueles ${ }^{20}$-, e, por outro lado, que a busca por segurança leve a uma concentração de poder nas mãos de poucos, uma vez que os governantes e, em particular, os reis, "não são deuses, mas homens que se deixam muitas vezes apanhar pelo canto das sereias"21. O principal problema com que Espinosa se confronta, portanto, diz respeito ao fato de que, se o único modo de vida seguro é estabili-

\footnotetext{
18 TTP, p. 385.

19 Cfr. ISRAËL, N. "La question de la sécurité dans le Traité politique” in JAQUET, C. SÉVÉRAC, P., SUHAMY, A. (eds.). La multitude libre. Nouvelles lectures du Traité politique. Paris: Éditions Amsterdam, 2008, pp. 81-93.

${ }^{20}$ Cfr. TP, II, § 9.

21 TP VII, $\S 1$, p. 64.
} 
zar os direitos naturais através de leis, esse processo envolve o risco de que um modelo de "segurança" seja imposto (para usar um termo do léxico político contemporâneo), que isola os indivíduos e os controla através de um dispositivo que mistura medo e confiança cega na ação das autoridades: para escapar desse risco, mais uma vez, é necessária uma estratégia coletiva 22 .

Cabe ao Capítulo V esclarecer os princípios dessa estratégia, que deve necessariamente envolver o maior número possível de cidadãos. De fato, se o direito de um Estado "se define pela potência da multidão" 23 , segue-se que somente a participação ativa da multidão de cidadãos torna possível produzir leis que atinjam o objetivo de uma comunidade política, ou melhor, "a paz e a segurança de vida, pelo que o melhor estado é aquele onde os homens passam a vida em concórdia e onde os direitos se conservam inviolados" 24. Emerge, a essa altura, uma definição de paz que se opõe explicitamente à famosa tese hobbesiana, que define a paz como o tempo residual em rela- ção ao tempo da guerra25; contrariamente, Espinosa escreve que "da cidade cujos súditos, tomados pelo medo, não pegam em armas, deve antes dizer-se que estão sem guerra do que dizer-se que têm paz. Porque a paz não é ausência de guerra, mas virtude que nasce da fortaleza de ânimo" 26 O conceito de segurança é assim redefinido com base em uma concepção "ativa" de paz, que retoma a mesma lógica encontrada nas últimas páginas do Tratado teológicopolítico e que pressupõe a possibilidade concreta de que a multidão possa exercer uma força de autoemancipação em relação às condições determinadas pelas leis e instituições.

A multidão - um nome que no Tratado Político define o conjunto de relações que vincula os indivíduos em uma comunidade política, ainda que em uma dimensão dinâmica e transformadora é, portanto, a portadora de uma liberdade específica, não explícita ou completamente racional. Novamente, o capítulo $\mathrm{V}$ afirma que a multidão livre "conduz-se mais pela esperança que pelo medo, ao passo que uma multidão subju-

\footnotetext{
${ }^{22}$ Sobre a natureza estratétgica do pensamento ético e político espinosano, cfr. BOVE, L. La stratégie du conatus. Affirmation et résistance chez Spinoza. Paris: Vrin, 1996.

23 TP, II, § 17 , p. 20.

$24 \mathrm{TP}, \mathrm{V}, \S 2$, p. 44.

25 "A natureza da guerra não consiste na luta real, mas na conhecida disposição para tal, durante todo o tempo em que não há garantia do contrário. Todo o tempo restante é de paz” (T. Hobbes, Leviatã, I, XIII, tradução livre).

$26 \mathrm{TP}, \mathrm{V}, \S 4$, pp. $44-45$.
} 
gada conduz-se mais pelo medo que pela esperança" 27. Nesse sentido, a multidão existe em função da liberdade, não porque a deseje conscientemente, mas porque pertence à sua natureza a tendência a se libertar - ao menos como uma fuga da solidão e da escravidão: uma liberdade necessária, embora enigmática, como a defendeu François Zourabichvili28 em um belo ensaio há alguns anos atrás.

Segundo Zourabichvili, a liberdade da multidão coincide com o problema político da transição de uma condição de escravidão para um regime de autonomia, talvez somente parcial. Isto significa que, para Espinosa, a liberdade não tem valor fundacional, não sendo um direito natural original que deve ser salvaguardado, nem é um princípio regulador que direciona a ação de um sujeito para um fim externo a ele; a liberdade é o índice de uma prática transformadora em contínuo devir, o resultado conjuntural e, ao mesmo tempo, dos processos de transformação sempre em ato da estrutura de uma comunidade.

Para retornar ao conceito espi- nosano de paz, creio que está claro que a concepção erasmiana, segundo a qual a paz coincide com a concórdia e a união fraterna dos homens, encontra no Tratado político uma reinterpretação política que pretende responder ao desafio proveniente do realismo maquiavélico e hobbesiano. Isso significa que, por um lado, o texto espinosano refuta uma concepção da concórdia puramente moral ou utópica, uma vez que não seria capaz de construir um Estado que garanta a segurança de seus cidadãos, no entanto, a paz não pode ser considerada como a mera ausência de conflito, já que "daquela cidade cuja paz depende da inércia dos súditos, os quais são conduzidos como ovelhas para que aprendam só a servir, mais corretamente se pode dizer uma solidão do que uma cidade" 29, O contraste - também terminológico - entre a "multidão" e a "solidão", que aparece nestas páginas, exprime com a máxima clareza o que definimos como estratégia política de Espinosa, o seu "realismo anômalo", como define Diego Tatián ${ }^{30}$, capaz de unir a força analítica de Maquiavel e Hobbes com

\footnotetext{
27 TP, V, § 6, p. 45.

28 ZOURABICHVILI, F. L'énigme de la "multitude libre" in JAQUET, C., SÉVÉRAC, P., SUHAMY, A. (orgs), La multitude libre. Nouvelles lectures du Traité politique, cit., pp. 69-80.

29 TP, V, § 4, p. 45.

30 TATIÁN, D. "Spinoza, un realismo anómalo de la paz" in Araucaria. Revista Iberoamericana de Filosofía, Política y Humanidades,16/32, 2014, pp. 93-109.
} 
uma perspectiva política que pretende dar efetividade aos processos coletivos de emancipação. A "solidão", de fato, não representa uma condição apolítica, uma espécie de retorno do estado de natureza, mas define aquele regime (que anteriormente era definido como "de segurança") no qual a potência comum da multidão está em seu grau mínimo, fazendo com que os cidadãos individuais vivam em uma condição de isolamento e indiferença mútuos - condição gerada pelo poder político -, o que torna extremamente difícil a comunicação e, com ela, a ativação de processos de mútuo acordo e colaboração.

Para combater esta tendência alimentada pela inércia e passividade própria das paixões tristes e da superstição que sempre, em certa medida, atravessam a multidão -, Espinosa desenvolve uma série de medidas institucionais que desempenham a tarefa de fortalecer os afetos alegres, contribuindo, assim, à produção de direitos coletivos comuns e ao fortalecimento da união e da concórdia dos ânimos. Vale a pena recordar rapidamente algumas dessas instituições da multidão (que se) liberta, uma para cada forma de governo: (1) o exército popular que, sobretudo em uma monarquia, impede o soberano de fazer guerra para seu ganho pessoal, e contra o interesse de seus súditos 31 , as formas de controle dos regimes aristocráticos por parte dos cidadãos, em particular o sistema de remuneração dos governantes, de tal modo que "para eles, seja de mais utilidade a paz do que a guerra" 32; (3) a abertura de cargos públicos para todos os cidadãos em uma democracia, o que impede que um grupo limitado de indivíduos monopolize os postos do governo ${ }^{33}$. No entanto, além das numerosas medidas de engenharia institucional que Espinosa propõe no Tratado Político, há também outro "instrumento" de fundamental importância - além das leis e instituições - para impedir a gênese de um regime baseado na solidão, qual seja, o direito de guerra que constitui o baluarte extremo da liberdade da multidão: de fato, se as leis de um Estado

\footnotetext{
31 Cfr. TP VI, § 10, p. 51: “O exército deve ser formado só por cidadãos, sem excetuar nenhum, e por mais ninguém, de maneira que todos tenham de ter armas e ninguém seja admitido no número dos cidadãos a não ser depois de ter preparação militar e se comprometer a exercitá-la em determinadas alturas do ano" .

32 TP, VIII, § 31 , p. 105.

33 Cfr. TP XI, § 1, p. 137: “todos aqueles cujos pais são cidadãos, ou que nasceram no solo pátrio, ou que são beneméritos da república, ou a quem a lei, por outros motivos, manda atribuir o direito de cidade, todos esses, digo, reclamarão para si o direito de voto no conselho supremo e de aceder por direito a cargos do estado, o qual não é lícito recusar-lhes a não ser devido a crime ou infâmia" .
} 
são de natureza tal que não podem ser violadas sem que ao mesmo tempo se debilite a robustez da cidade, isto é, sem que ao mesmo tempo o medo comum da maioria dos cidadãos se converta em indignação, a cidade, por isso mesmo, dissolve-se e cessa o contrato, o qual, por conseguinte, não é defendido pelo direito civil mas pelo direito de guerra 34 .

A referência a um "direito" (ou melhor, a uma "força", para não cair no equívoco de pensar em um Espinosa monarcômaco) que excede o nível do direito estatal também está presente nas páginas conclusivas do Tratado teológicopolítico, onde se afirma que na maioria dos homens há uma tendência inevitável para resistir à opressão, a ponto de "julgarem que é uma coisa mais honesta e não uma vergonha que não seja somente com as pretensões de crimes" 35 .

Para concluir: nas páginas dos dois tratados políticos espinosa- nos, mesmo que trilhando percursos diferentes, é apresentada a mesma tentativa de repensar a concepção humanista de paz e concórdia após o desafio trazido pelo realismo antropológico e político de Maquiavel e Hobbes. Para tornar eficaz o projeto de Erasmo, é necessário "politizálo", ou melhor, reconhecer que só é possível através do envolvimento ativo da multidão, em cuja potência se radica a busca do bem comum (a res publica), se não para garantir a paz de forma definitiva, pelo menos para impedir que se transforme em solidão e subserviência ao poder de um. Somente uma prática comum que põe em jogo a imaginação, os afetos e a razão coletivas pode gerar uma paz que consiste não apenas em evitar a morte, mas também e sobretudo no "cultivar a vida". Por essa razão, não pode haver uma condição de paz que não seja também uma condição de liberdade, tanto individual quanto coletiva: uma liberdade sempre por recomeçar, ou, como escreve Marilena Chaui, por "introduzir o novo no mundo" 36 , contra a repetição interminável e mortal da guerra e da escravidão.

\footnotetext{
34 TP IV, § 6, p. 41.

35 TTP XX, p. 388.

36 CHAUI, M. "Segurança e liberdade: Espinosa e a construção da paz" in Discurso, 35, 2005, pp. 158-159.
} 


\section{Referências}

BIETENHOLZ, P.G. Encounters with a Radical Erasmus: Erasmus' Work as a Source of Radical Thought in Early Modern Europe, Toronto: Toronto University Press, 2009.

BOVE, L. La stratégie du conatus. Affirmation et résistance chez Spinoza. Paris: Vrin, 1996.

CHAUI, M. "Segurança e liberdade: Espinosa e a construção da paz" in Discurso, 35, 2005.

ESPINOSA, B. Tratado Teológico-político. Tradução, introdução e notas de Diogo Pires Aurélio. Lisboa: Imprensa Nacional-Casa da Moeda, 2004.

ESPINOSA, B. Tratado Político. Tradução, introdução e notas de Diogo Pires Aurélio, revisão de Homero Santiago. São Paulo: WMF Martins Fontes, 2009.

FIX, A.C. Prophecy and Reason. The Dutch Collegiants in the Early Enlightenment, Princeton: Princeton University Press, 1990.

HAITSMA MULIER, E.O.G. "A Controversial Republican: Dutch Views on Machiavelli in the Seventeenth and Eighteenth Centuries" in BOCK, G., SKINNER, Q., VIROLI. M. (orgs.); Machiavelli and Republicanism. Cambridge: Cambridge University Press, 1990.

ISRAËL, N. "La question de la sécurité dans le Traité politique" in JAQUET, C. SÉVÉRAC, P., SUHAMY, A. (eds.). La multitude libre. Nouvelles lectures $d u$ Traité politique. Paris: Éditions Amsterdam, 2008.

JAMES, S. "Narrative as the means to freedom: Spinoza on the uses of imagination" in MELAMED, Y.Y., ROSENTHAL, M.A. (orgs.). Spinoza's Theological-Political Treatise. A Critical Guide. Cambridge: Cambridge University Press, 2010.

NADLER, S. Spinoza. A Life, Cambridge: Cambridge University Press, 1999.

SKEAFF, C. Becoming Political. Spinoza's Vital Republicanism and the Democratic Power of Judgment, Chicago: Chicago University Press, 2018.

TATIÁN, D. "Spinoza, un realismo anómalo de la paz" in Araucaria. Revista Iberoamericana de Filosofía, Política y Humanidades,16/32, 2014.

ZOURABICHVILI, F. "L'énigme de la 'multitude libre' " in JAQUET, C., SÉVÉRAC, P., SUHAMY, A. (orgs), La multitude libre. Nouvelles lectures 
du Traité politique, Paris: Éditions Amsterdam, 2008.

Recebido: 04/07/2019

Aprovado: 09/11/2019

Publicado: 17/11/2019 
